\title{
COMPREHENSIVE NUMERICAL SIMULATION OF WAVES CAUSED BY TYPHOON USING A METEOROLOGY-WAVE-STORM SURGE-TIDE COUPLED MODEL
}

\author{
Koichiro Ohira ${ }^{1}$, Tomoya Shibayama ${ }^{2}$, Miguel Esteban², Takahito Mikami², \\ Tomoyuki Takabatake ${ }^{3}$ and Makito Kokado ${ }^{4}$
}

\begin{abstract}
The present study focuses on the risks of storm surge caused by future increases in typhoon intensity due to climate change. These risks were analyzed by integrating weather, wave, storm surge and tide prediction systems into a new simulation methodology. This model, which the authors developed by themselves, makes it possible to calculate the weather fields of typhoons in the past as well as in the future on the basis of meteorology and can simulate waves in a complex geographical area, in contrast with many previous storm surge simulation methods which were not based on accurate meteorological models. The model was verified to accurately reproduce historical typhoons and waves and thus is a useful tool for the analysis of future climate risks.
\end{abstract}

Keywords: Storm surge, Climate change, WRF, SWAN, Nao.99b

\section{INTRODUCTION}

Japan is recognized to be one of the countries that are most vulnerable to natural disasters, as it is frequently affected by earthquakes, typhoons and other events. Especially, attention to coastal risk management has dramatically increased following the March 2011 Tohoku tsunami (e.g. Mikami et al. (2012); Mori et al. (2011); Sasaki et al (2012)). However, although tsunamis are indeed very dangerous events, they are far less frequent than typhoons and the storm surges caused by them, which regularly affect Japanese coastal areas. Typhoons and storm surges have inflicted enormous damage to Japanese society, such as for example that caused by Typhoon Vera (Isewan Typhoon, 1959).

In these last few years, especially since the IPCC 4AR Report was published, not only scientists but also the general public has acknowledged that anthropogenic climate change is a serious global problem. According to IPCC 4AR Report (2007), there is a general agreement that tropical cyclones are likely to increase in intensity, though there is no consensus yet on the future frequency of these events. Pielke (2007) also highlights the uncertainties regarding future changes in tropical cyclone intensity, and reports how nine of the leading scholars on tropical cyclones and climate change give estimates ranging from a zero to 36 per cent increase in tropical cyclone intensity by the year 2100 . More recently Knutson et al.(2010) summarized all the most important work on tropical cyclone simulations, including recent research that was done using higher resolution models than those used in the work that led to the IPCC 4AR. Their review suggests that the intensity of tropical cyclones in the future could increase by between 2 and $11 \%$ by 2100 . This could have important consequences for the flooding of coastal areas (Hoshino et al. 2011), port infrastructure and operations (Esteban et al., 2009) and the Japanese economy in general (Esteban et al., 2011).

Although the intensification of typhoons and storm surge due to climate change can have negative impacts in coastal areas, the method to forecast these storm surges has so far relied on simplistic simulation methods. Although the simulation of the wave field can be well approximated by the use of programs such as SWAN, the simulation of the typhoon wind field is generally too simple, leading to a general lack of accuracy. For example, Takagi et al (2009) calculated of the waves due to a typhoon that had been artificially increased in intensity by simulating the weather field and multiplying the original weather data by a certain intensity multiplier. However, this method cannot simulate the local weather field in a complex geographical area because of uncertainty in this intensity multiplier and the roughness of the grid size of the topography data. Conventional research about forecasting future storm surges simulates typhoons by setting the central pressure the typhoon, the maximum wind speed, the radius of maximum wind and then substituting these values into Myers equation and other simplified and approximated equations such as Kato's equation(2005).

However, these methods have substantial problems associated with them as they ignore many important processes, such as terrain effects and internal structural change at each step of the life cycle of the typhoon, which can considerably affect the accuracy of the simulation.

\footnotetext{
${ }^{1}$ Chubu Electric Power Company, 5-5 Mikuralbigawa-cho, Ibi-gun, Gifu Pref.,501-0704, Japan

${ }^{2}$ Dept. of Civil and Environmental Engineering, Waseda University,3-4-1Okubo, Shinjuku-ku, Tokyo, 169-8555, Japan

${ }^{3}$ Taisei Corporation, 1-25-1Nishi-Shinjuku,Shinjuku-ku, Tokyo, 163-0606, Japan

${ }^{4}$ Hitachi Ltd, 2-4-18 Toyo, Koto-ku, Tokyo, 135-8633, Japan
} 
Yoshino et al. $(2005,2011)$ carried out research on how to precisely simulate a typhoon and considerably improved the accuracy of storm surge models by integrating MM5 (The Fifth-Generation NCAR/Penn State Mesoscale Model, which is a local weather forecasting model) into a storm surge model. Mase et al. $(2005,2011)$ researched how to precisely forecast storm surge by integrating WRF (Weather Research and Forecasting model, which is considered as the successor model of MM5) and a wave prediction model. However, a methodology to simulate future typhoons, together with the waves and storm surge associated with them is something that has not been researched up to present. Thus, the present paper attempts to simulate future climate change intensified typhoons by using a meteorological model coupled with wave and storm surge models. The simulation developed by the authors essentially integrated WRF (Weather Research and Forecasting), SWAN (Simulating Waves Nearshore: Ver. 40.85), Storm surge stimulation models and the NAO.99b tidal prediction system. This comprehensive model makes it possible to calculate weather fields of typhoons on the basis of meteorology and simulate waves (including wind driven surges, pressure surges and tides) in a complex geographical area.

In addition, the study will consider the necessity of disaster protection countermeasures against future climate change by quantitatively verifying how future wave and storm surge could change comparing with present day conditions. Typhoon Fitow (2007) will be used as a case study, with the storm surge caused by this typhoon being compared with a typhoon that approached the computational domain with the same strength at Fitow in 2007, but with the climate conditions for computational domain being altered to resemble those of the year 2100. Tokyo Bay, which is surrounded by land and hence constitutes a difficult area to accurately forecast weather fields, was set as the target computational domain in order to verify the accuracy of the system.

\section{NUMERICAL MODEL}

Outline of a meteorology-wave-storm surge-tide coupled model

The simulation methodology developed by the authors consists of 4 separate models that are coupled together: WRF (Weather Research and Forecasting model; Ver, 3.3.1), SWAN (Simulating Wave Nearshore; Ver. 40.85) , STOM (STOrM surge model) and Nao99b (Matsumoto et al., 2000). Together, they have been designated as OSIS (Ohira Shibayama Integrated Storm surge model). The model flow is shown in Figure.1.

Integrating the four models, (meteorology, wave, storm surge and tidal model) is important to simulate real wave conditions and to improve the accuracy of the calculation. The reason for integrating wave, storm surge and tide model is that the wave height due to the typhoon consists of a wave and storm surge (pressure surge and wind driven surge) components, together with the tide. Hence, it is important to calculate these 3 elements simultaneously to simulate real waves, as shown in Figure 1.

One of the key components of the system is the WRF element. WRF is an advanced meso-scale weather forecasting model developed jointly by NCAR (The National Center for Atmospheric Research) and more than 150 other organizations. In the present study, WRF performs the weather prediction by loading FNL as input data, which is a 1 degree reanalysis meteorological data published by NCAR. Regarding FNL, which is also a weather forecasting tool, the initial condition is constructed with both the observed data 6 hours from the synoptic time and the prediction result of the next calculation cycle which comes out from the previous result. This 6-hour interval data can be found in the internet (CISL Research Data Archive, 2012). The calculation of WRF was conducted with supercomputer "HA8000" of the Information Technology Center in the University of Tokyo. It takes approximately one hour of computational time to calculate one hour of the typhoon simulation by using parallel computation with 4 nodes. This WRF model consists of motion equation, mass conservation, geopotential equation, potential temperature, Scalar conservation, equation of state and so on.

SWAN is a third generation wave model developed by Delft University of technology that computes random, short-crested wind-generated waves in coastal regions and inland waters. STOM is a model that improved the storm surge model of Shibayama et al (1990) by loading the wind and pressure field from WRF. It uses the nonlinear long wave equation, which is given by eqs.(7) and (8), to simulate the effects of the pressure and wind driven surges. The continuity and motion equations are given below, where $A_{h}$ is the horizontal mixing coefficient. 


$$
\begin{aligned}
& \frac{\partial \eta}{\partial t}+\frac{\partial M}{\partial x}+\frac{\partial N}{\partial y}=0 \\
& \frac{\partial M}{\partial t}+\frac{\partial}{\partial x}\left(\frac{M^{2}}{D}\right)+\frac{\partial}{\partial y}\left(\frac{M N}{D}\right)+g D \frac{\partial \eta}{\partial x}-f N+\frac{D}{\rho_{w}} \frac{\partial p}{\partial x}-\frac{\tau_{s x}}{\rho_{w}}+\frac{\tau_{b x}}{\rho_{w}}-A_{h}\left(\frac{\partial^{2} M}{\partial x^{2}}+\frac{\partial^{2} M}{\partial y^{2}}\right)=0 \\
& \frac{\partial N}{\partial t}+\frac{\partial}{\partial x}\left(\frac{M N}{D}\right)+\frac{\partial}{\partial y}\left(\frac{N^{2}}{D}\right)+g D \frac{\partial \eta}{\partial y}-f M+\frac{D}{\rho_{w}} \frac{\partial p}{\partial y}-\frac{\tau_{s y}}{\rho_{w}}+\frac{\tau_{b y}}{\rho_{w}}-A_{h}\left(\frac{\partial^{2} N}{\partial x^{2}}+\frac{\partial^{2} N}{\partial y^{2}}\right)=0
\end{aligned}
$$

The Nao.99b model, which was developed by National Astronomical Observatory of Japan, is a global ocean tide model representing the major 16 tidal constituents with a spatial resolution of $0.5^{\circ}$. These were estimated by assimilating about 5 years of TOPEX/POSEIDON altimeter data into a barotropic hydro dynamical model which can simulate not only past but also future tides.

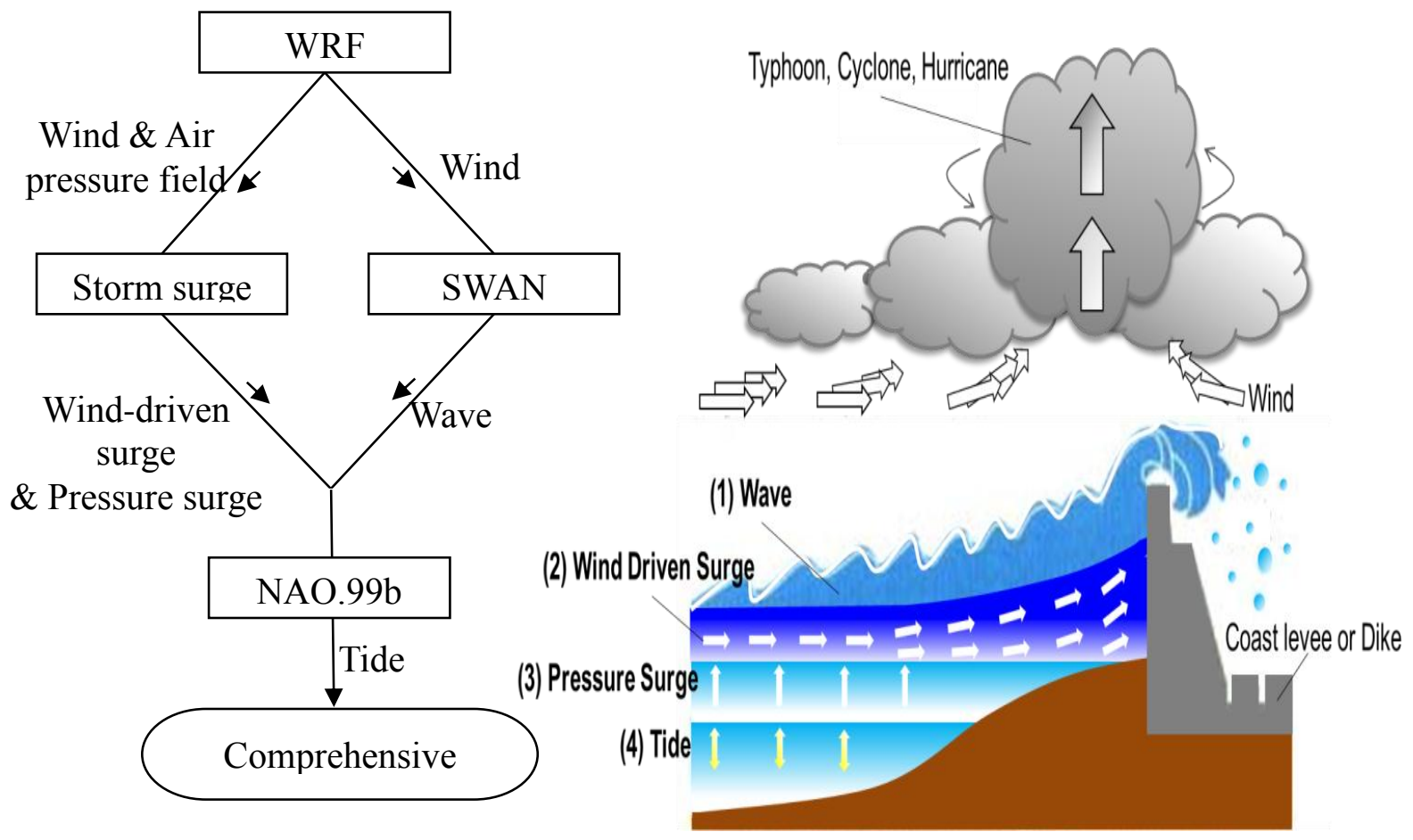

Figure 1. Model flow- OSIS and composition of typhoon wave

\section{Target typhoon and calculation conditions}

To verify the accuracy of the models the authors attempted to reproduce the storm surge and wave conditions that took place during the passage of Typhoon Fitow (2007). Table 1 outlines some of the key characteristics of this storm. The typhoon passed through the Kanto region that surrounds Tokyo Bay, inflicting considerable damage along its path. It made landfall in the southern part of $\mathrm{f}$ Izu Peninsula in Shizuoka Prefecture. at $3 \mathrm{pm}$ on $6^{\text {th }} \mathrm{Sep}(\mathrm{UTC})$ and advanced northward straight through the Kanto region, as shown in Figure 2. The wave and storm surge caused by the storm caused the collapse of the Seisho bypass into the sea, amongst other damage.

The different parameters used in the simulation are summarized in Table 2. The simulation was carried out with a relatively high resolution, using a minimum $900 \mathrm{~m}$ grid size in all of the models.

\begin{tabular}{|c|c|c|c|}
\hline \multicolumn{5}{|c|}{$\begin{array}{c}\text { Table 1. Outline of target typhoon. } \\
\text { (Reference: JMA) }\end{array}$} \\
\hline Typhoon & $\begin{array}{c}\text { Developmental period } \\
\text { (UTC) }\end{array}$ & $\begin{array}{c}\text { Minimum central } \\
\text { pressure }(\mathrm{hPa})\end{array}$ & $\begin{array}{c}\text { Maximum peak wind } \\
(\mathrm{m} / \mathrm{s})\end{array}$ \\
\hline Typhoon Fitow & $\begin{array}{c}0: 00.29 . \text { Aug. 2007 } \\
0: 00.8 \text {. Sep, 2007 }\end{array}$ & 965 & 35 \\
\hline
\end{tabular}




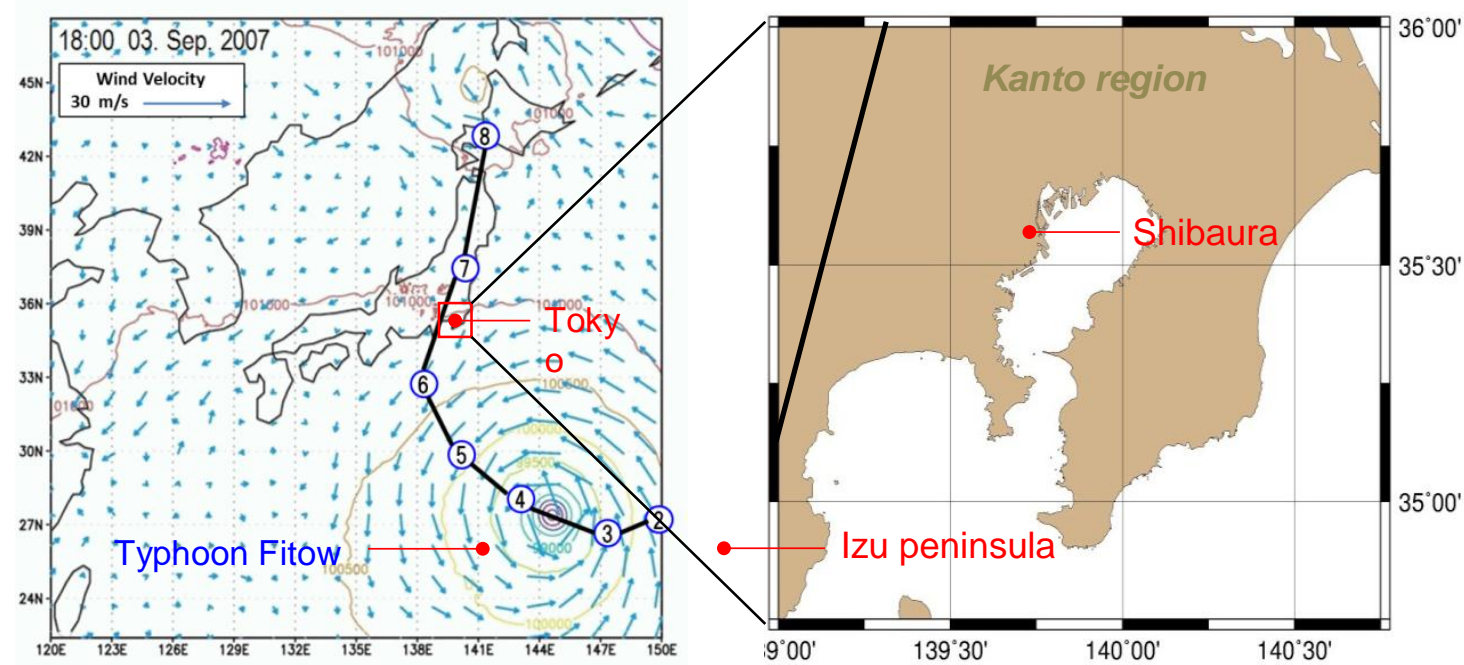

Figure 2. Track of Typhoon Fitow (left: around Japan, right: around Kanto region)

\begin{tabular}{|c|c|c|}
\hline \multicolumn{3}{|c|}{ Table 2. Calculation condition. } \\
\hline \multirow{9}{*}{$\begin{array}{c}\text { Weather model } \\
\text { WRF }\end{array}$} & Time (UTC) & Sep. $3^{\text {rd }} 18: 00(2007) \sim$ Sep. $9^{\text {th }} 18: 00(2007)$ \\
\hline & Area I & N34.4366 36.1526, E138.748 140.854 \\
\hline & Area II & N34.8362 35.7404, E139.476 140.197 \\
\hline & Horizontal grid & I: $80 \times 80, \quad$ II :139×91 \\
\hline & Horizontal resolution & I: $2700 \mathrm{~m}$ II: $900 \mathrm{~m}$ \\
\hline & Projection & Mercator \\
\hline & Vertical layer number & 27 Layers \\
\hline & Time Step & I: $15(\mathrm{sec})$ II: $5(\mathrm{sec})$ \\
\hline & Topography data & USGS \\
\hline \multirow{8}{*}{$\begin{array}{l}\text { Wave model } \\
\text { SWAN }\end{array}$} & Time (UTC) & Sep. 3rd 18:00 (2007) Sep.9th 18:00 (2007) \\
\hline & Area & N34.8 35.7, E139.5 140.2 \\
\hline & Time Step & $3(\mathrm{sec})$ \\
\hline & Horizontal resolution & $900 m$ \\
\hline & Horizontal grid & $139 \times 91$ \\
\hline & Projection & Mercator \\
\hline & Physics model & Komen \\
\hline & Topography data & GEBCO \\
\hline \multirow{8}{*}{$\begin{array}{l}\text { Storm Surge } \\
\text { STOM }\end{array}$} & Time (UTC) & Sep. 3rd 18:00 (2007) Sep.9th 18:00 (2007) \\
\hline & Area & $\mathrm{N} 34.8 \sim 35.7, \quad \mathrm{E} 139.5 \sim 140.2$ \\
\hline & Time Step & $3(\mathrm{sec})$ \\
\hline & Vertical layer number & 2 Layers \\
\hline & Horizontal resolution & $900 m$ \\
\hline & Horizontal grid & $138 \times 90$ \\
\hline & Projection & Mercator \\
\hline & Topography data & GEBCO \\
\hline \multirow{2}{*}{$\begin{array}{l}\text { Tidal model } \\
\text { NAO.99b }\end{array}$} & Time (UTC) & Sep. 3rd 18:00 (2007) Sep.9th 18:00 (2007) \\
\hline & Area & Each point \\
\hline
\end{tabular}




\section{Verification of the calculation results}

The wind, storm surge and wave caused by typhoon Fitow were simulated using the method described in the previous section and compared to data recorded at various stations throughout Tokyo Bay. This data is available at various internet sites (JMA, NOWPHAS, Bureau of Port and Harbour Tokyo Metropolitan Government).

Figure 3 shows the time series of the water level at Shibaura throughout the passage of the typhoon over Tokyo, with the horizontal axis (and those in Figures 4-7) showing the Coordinate Universal Time(UTC). This water level is the result of several inter-related phenomena, and includes the waves created by the strong winds, the storm surge (composed in turn of the pressure and wind driven surges) and the tide. This figure also shows a comparison between the observed values during the passage of the typhoon, those calculated using a traditional storm surge model and those by OSIS. These observed values (and those in subsequent figures 4-7) are from Bureau of Port and Harbor Tokyo Metropolitan Government. Figure 3 highlights how the values obtained from OSIS estimate both the maximum water level and its evolution through time more faithfully than traditional storm surge models.

The model used is also able to accurately reproduce both the wind and wave fields associated with the typhoon. Figure 4 shows the observed and calculated values of wind speed (for WRF and other models). The line indicated as 'Previous Model' in the figure is the calculation value of wind from a 2D experimental typhoon model, 'GFS_anl' is the 1 degree mesh observed data of weather which is published by NCEP (National Centers for Environmental Prediction) and 'MSM' is the $5 \mathrm{~km}$ mesh of weather data published by JMA (Japan Meteorological Agency). From this figure it is clear that WRF is able to simulate the wind field more precisely than the 'Previous Model'.

Figures 5(a), (b) show the calculated and observed values of the significant wave height and period at Shibaura, respectively. In both case the results show how the simulation is able to accurately calculate both the maximum values and the general trend of both of these parameters throughout the passage of the typhoon.

Figure 6 shows the comparison between the storm surge calculated by STOM, the 2D experimental typhoon model and the observed data. The observed data from 0:00 to 4:00 on Sep.7 shows a substantial vertical drop in height from $3.3 \mathrm{~m}$ to $1.2 \mathrm{~m}$, which is thought to be due to an error in the observational equipment asthe typhoon apprroached. At this point the eye of typhoon was passing through the northen side of the map shown in Figure 2. In this case, STOM was not able to accurately capture the maximum storm surge, though it still reproduces this phenomenon better throughout the passage of the typhoon than the 2D method, as seen in Figure 6.

Figure 7. shows the comparison between the calculated values of the Nao.99b model and the observed tidal data. Again, the observed data shows the sharp drop that was probably caused by equipment malfunction. Although there is a significant difference between the observed and calculated values throughout the passage of the strom (for the 24 hours from 12:00 Sep.24), the reason for this is not a calculation error but the fact that the data at this time includes the sea level rise by storm surge.

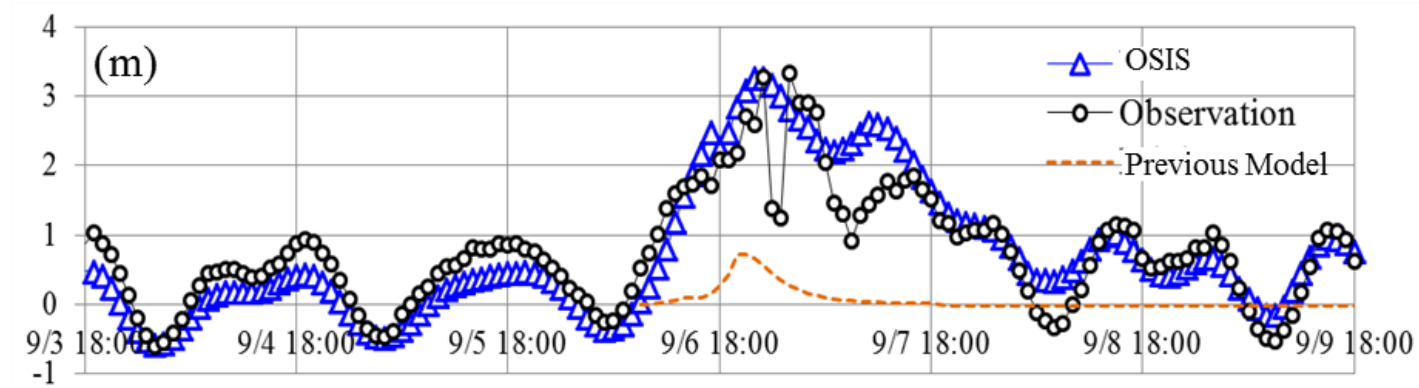

Figure 3.Total wave height $(=$ wave + storm surge + tide $)$ at Shibaura 


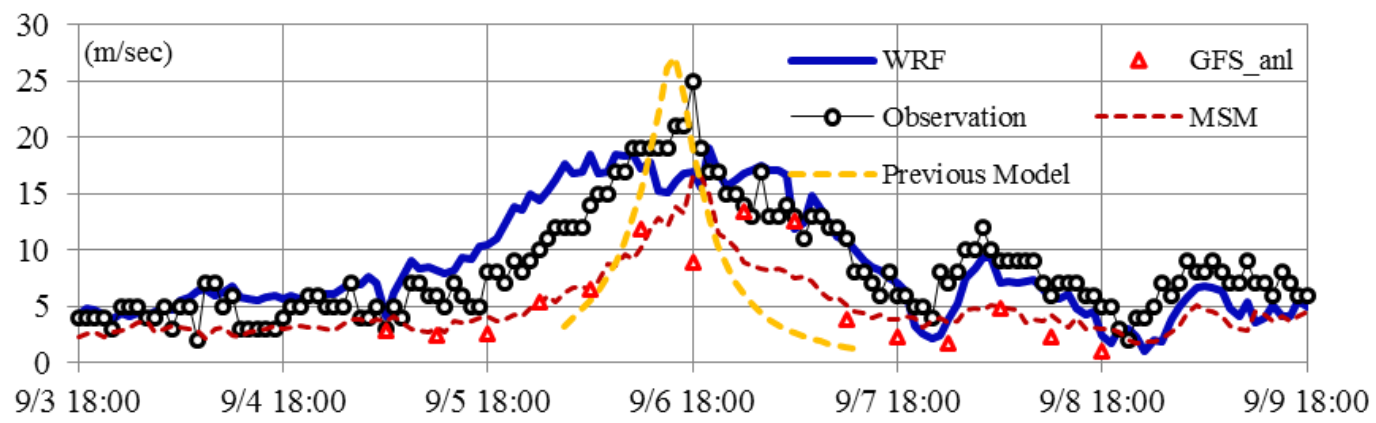

Figure 4. WRF, wind speed at Shibaura

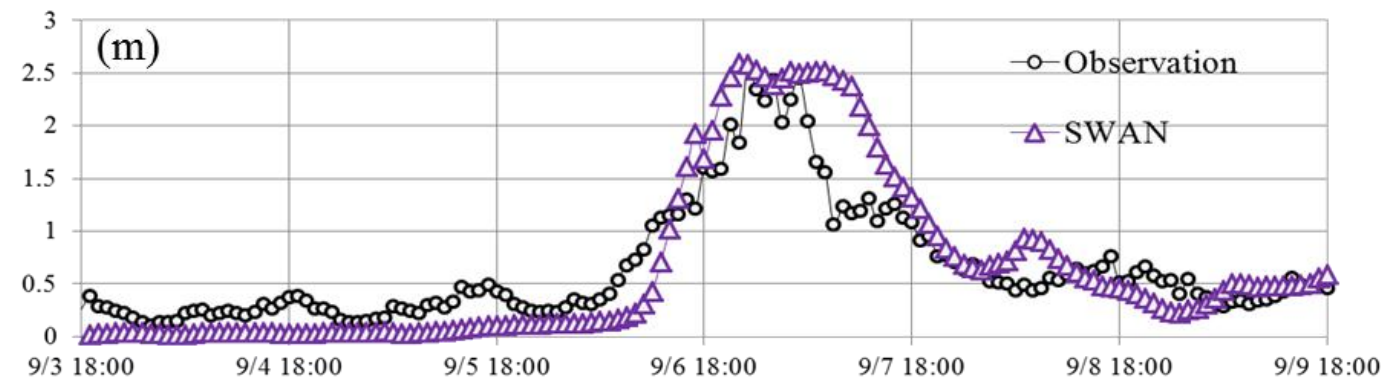

Figure 5(a). SWAN, Significant wave height at Shibaura

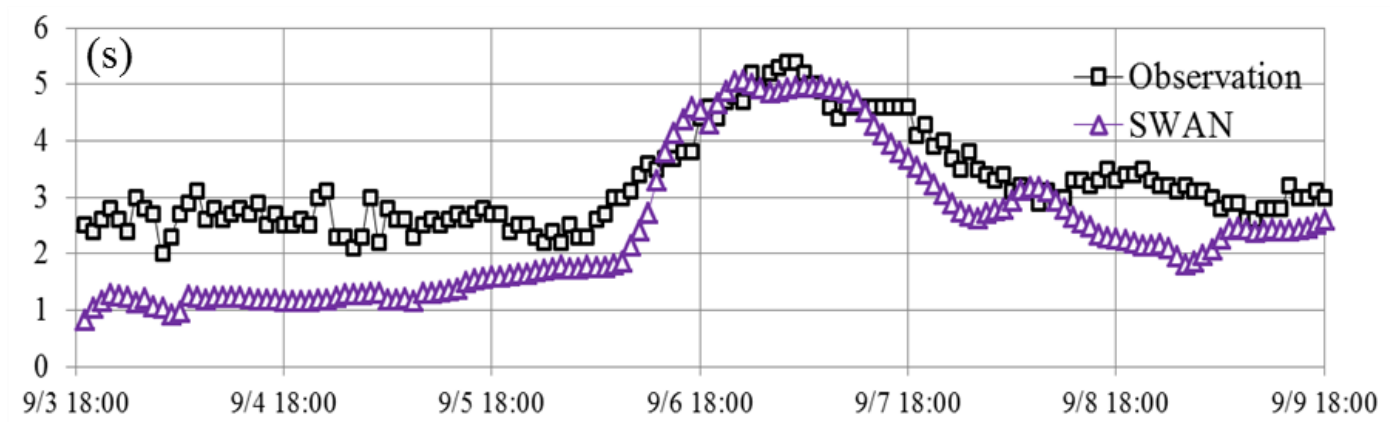

Figure 5(b). SWAN, Significant wave period at Shibaura

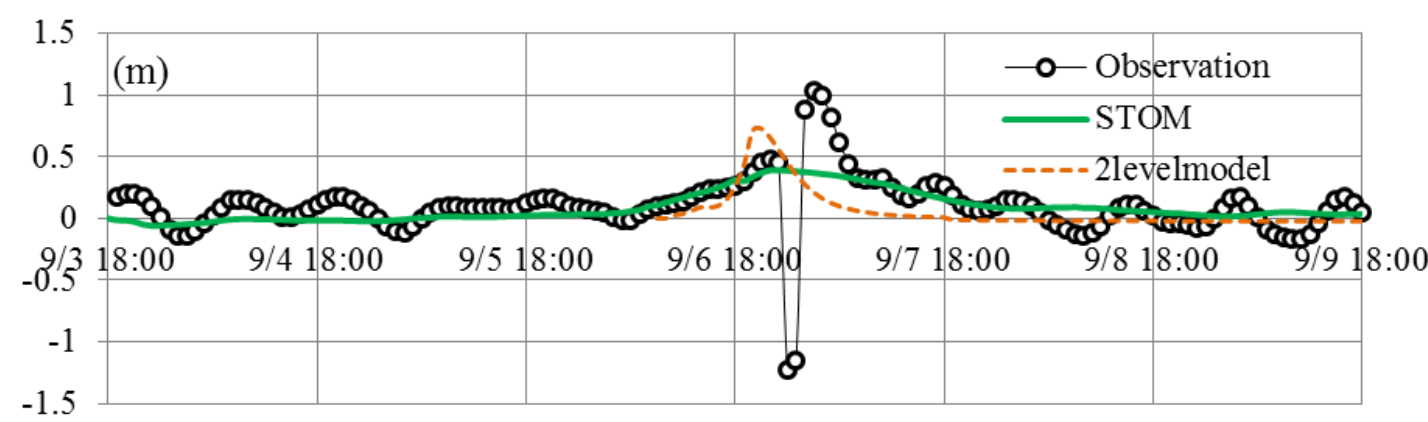

Figure 6. STOM, Storm surge (= wind driven surge + pressure surge) at Shibaura 


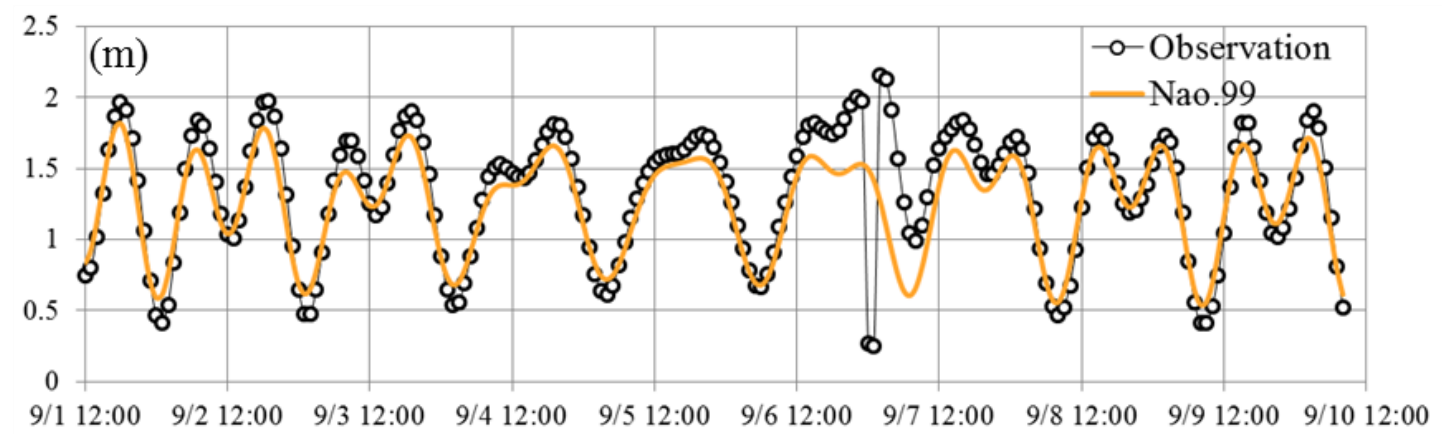

Figure 7. Nao99b, Tide at Shibaura

\section{WAVE AND STORM SURGE IN THE YEAR 2100}

\section{Calculation procedure}

Typhoon Fitow in 2007('Fitow2007') was used as a base to analyze the possible effects that climate change by the year 2100 could have on a typical typhoon crossing Tokyo Bay. In order to do this, the simulation procedure was altered slightly to see how a typhoon of the same characteristics such as Fitow would change due to the warmer weather conditions around Tokyo Bay expected in the year 2100. The storm surge and weather field were also obtained, in order to gain an understanding of how the damage due to these types of events could be amplified in the future.

However, the process to simulate past typhoons and future typhoons is slightly different, as it is necessary to create the weather field in the year 2100 as input weather data before executing WRF. Merely using the historical data for Fitow and increasing the temperature of the whole domain, however, does not produce good results, as the typhoon will not necessarily follow the same track as that of Fitow in 2007. In order to solve this problem it is thus necessary to use two different techniques, one for creating the future weather field and another one for creating the future typhoon (which is often referred to in literature as a "typhoon bogus"). By doing this, the weather field in the year 2100 can be created, and then this "typhoon bogus" is artificially inserted in the weather field, and made to follow the same course as the historical event.

To create the weather field in the year 2100 the FNL historical data for Typhoon Fitow was edited to incorporate future increases in global temperatures. FNL 3D data is written in a type of binary code called 'grib format', which includes over 50 parameters. In the present work, 2 ways were used to edit the original FNL data, one by means of a Fortran program and the other through an editing ungrib program (which is one of the programs present in WRF). The creation of the 2100 weather field uses the results of Northern Pacific Ocean General Circulation Model (NPOGCM) A1B scenario (2008) published by the Japan Meteorological Agency (JMA) as a reference. According to these results, sea surface temperature (SST) around Tokyo Bay will increase by +2.1 degrees and see level will increase by $0.2 \mathrm{~m}$ by 2100 , as shown in Figure 8 . So the 2100 weather field was created by increasing the SST by 2.1 degrees. The total water level height during the passage of the typhoon in the future would thus be the sum of the wave, storm surge and tide plus the amount of sea level rise in Tokyo Bay according to this A1B scenario

The second step is to create a "typhoon bogus" by using a certain simulation routine, present as an option in WRF after version 3.3. The "typhoon bogus" that was used had the same characteristics as the historical typhoon "Fitow", i.e. the central pressure and wind strength of the typhoon was not altered before it reached the computational domain (in contrast to what other authors usually do, such as Takagi et al. 2011 or Esteban et al., 2009). Thus, the purpose of the present simulation was to study what would be the effect of an increase in SST around Tokyo Bay on the strength of a present day typhoon (as opposed to one which would have increased in intensity, according to what is shown in Knutson et al. 2010). 



Figure 8. Increase in SST an SLR by the year 2100 for different regions of Japan

\section{Results}

By using the methodology described in the previous section it is possible to compare the damage potential between the present day Fitow typhoon ("Fitow2007") and the same typhoon in a future where SLR and SST are higher than at present ("Fitow2100"). Figure 9 shows the comparison between the maximum waters level (which results from the addition of the wave, storm surge, tide and SLR) between Fitow2100 and Fitow2007 at different points throughout Tokyo Bay. The wave height at Shibaura, Edogawa, Funabashi and Chiba, which are located in the inner side of the bay, are higher than those at Futtsu and Tateyama, which are situated in the entrance of the bay.

Figure 9 shows how for the entire extension of Tokyo Bay the water levels that result from the conditions in Fitow2100 are about $1.5 \mathrm{~m}$ higher than those in Fitow2007. Much of these increases in water levels come from higher wave heights. Sea wave are caused by wind so as this increases in strength so do the waves increase in height. Although the present simulation did not increase the intensity (and hence wind speed) of typhoon Fitow before it reached the computational domain, the increase in SST inside the area studied results in a stronger typhoon compared to the historical event, leading to stronger winds and thus higher waves.

Figure 10 shows the wind speed calculated for Fitow2100 by WRF at Shibaura. The peak wind speed is higher than that of Fitow2007, as SST increases will lead to higher quantity of seawater evaporation. The latent heat, which is source of energy of typhoons, increases along with the quantity of evaporation, leading to an intensification of the typhoon. Figure 11 shows the results of the SWAM simulation for the significant wave height and periods at Shibaura. As a result of these increases in wind speed the significant wave height becomes 1.5 times higher than in the case of Fitow2007, while the significant period is 1.2 second longer.

Figure 13 shows the result of the STOM model, showing how the storm surge for Fitow2100 is only $0.1 \mathrm{~m}$ higher than in the case of Fitow2007. The reason for this small increase is that, while for the case of the wind there is a big difference between Fitow2100 and Fitow2007, for the case of the atmospheric pressure the difference between the future and present events is very small. This indicates that most of the increase in storm surge is due to the increase in the wind driven surge rather than the pressure surge.

Finally, all these components, together with the tide prediction obtained from Nao.99b, are put together in Figure 9. This figure also highlights how most of the increases in storm surge in the future will be down to increases in wave heights that result from the stronger winds that will take place due to the passage of the typhoon. 


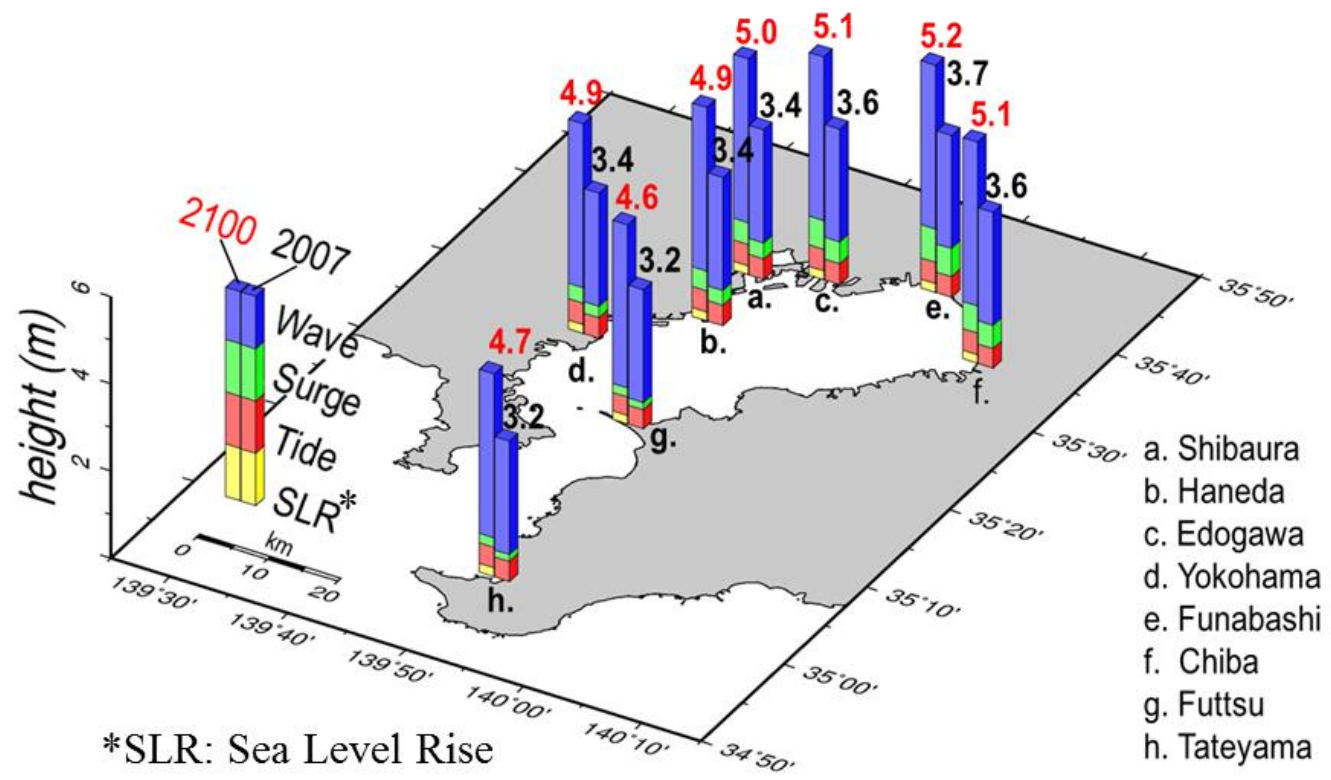

Figure 9. Comparison of storm surge components between Fitow2007 and Fitow2100

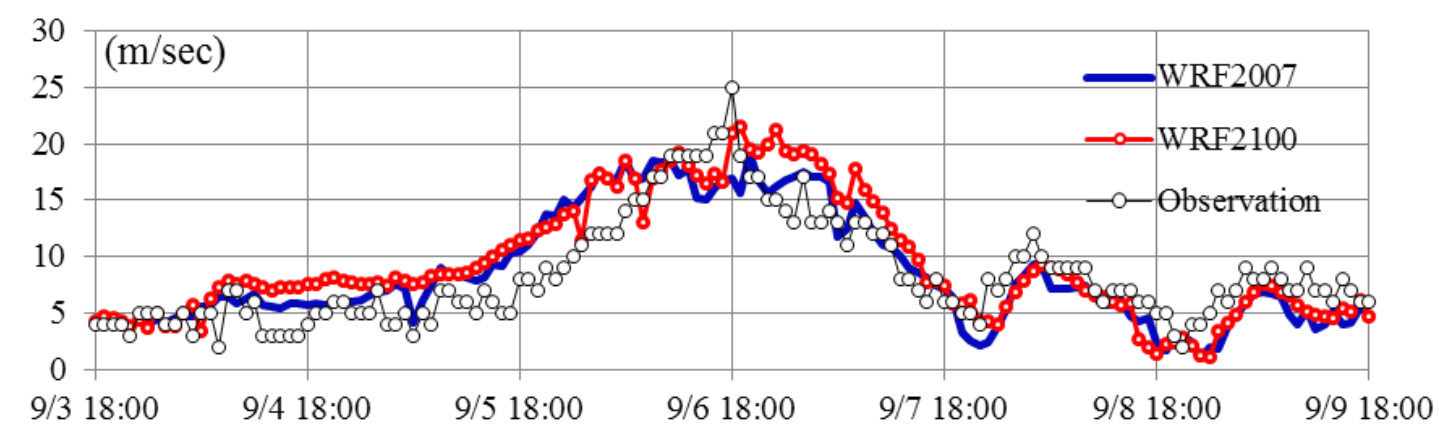

Figure 10. WRF, Wind speed of Typhoon Fitow2100 at Shibaura

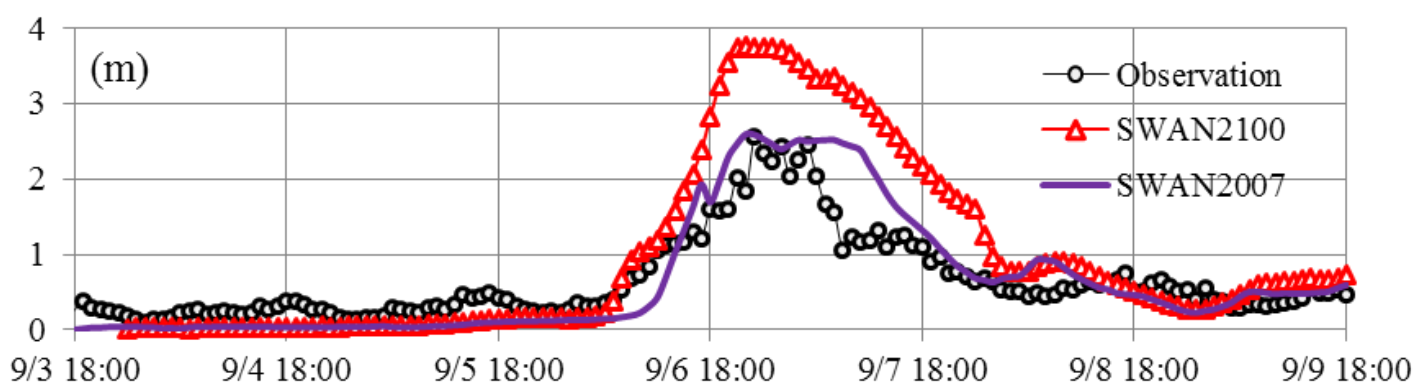

Figure 11(a). SWAN, Significant wave height of Fitow2100 at Shibaura

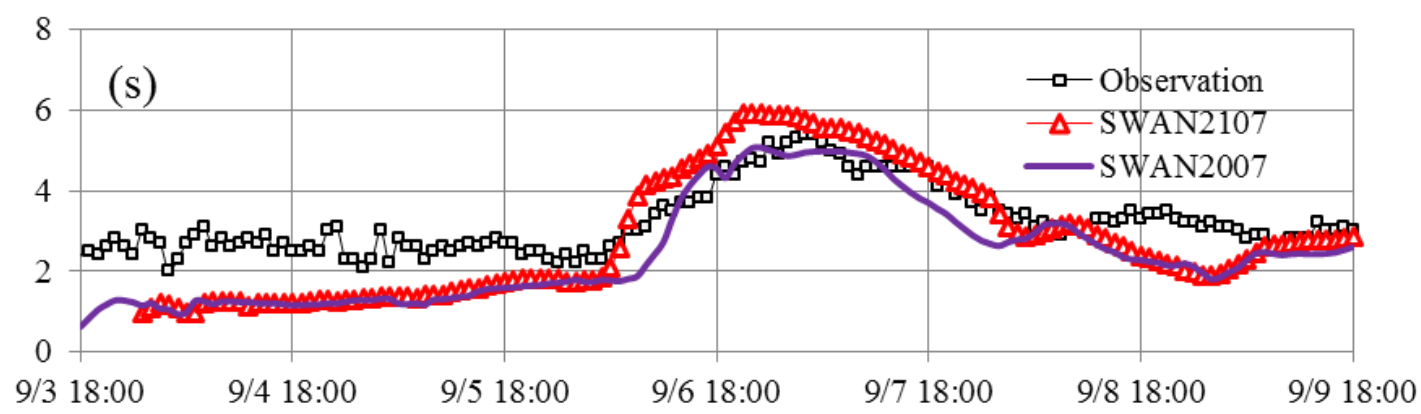

Figure 11(b). SWAN, Significant wave period of Fitow2100at Shibaura 




Figure 12. STOM, Storm surge of Fitow2100 at Shibaura

\section{DISCUSSION}

There are a number of problems associated with the present methodology, all of which can help to explain some of the lack of accuracy in the calculations. One of the main problems relates to the size of the target domain, which included only the Kanto region but did not cover the point where the typhoon originated or were it dissipated. Due to this, the central pressure of the typhoon and its track could not be analysed in as much detail as would have been desirable. This can lead to an under-estimation of the central pressure of the typhoon, and which can explain the lack of accuracy in this element of the calculation, as shown in Figure 6. It is important to remember that by using the simulation parameters shown in the present work each hour of typhoon simulation also required one hour of super-computer time. In order to calculate a larger domain it would be necessary to use multiple nests, though even under these conditions the computational time can be prohibitive. Thus, the authors chose not to use a more enlarged simulation area, as this would have made the computational time unrealistically long.

Regarding the climate change simulation, there is much uncertainty regarding some of the parameters used. During the 20th century the global average sea level rose by an average of around $1.7 \mathrm{~mm}$ per year, with satellite observations showing that since 1993 sea level has been rising at a rate of around $3 \mathrm{~mm}$ per year, according to the 4th Assessment Report of the Intergovernmental Panel on Climate Change, or IPCC 4AR. Future projections of sea level rise by the IPCC 4AR show that sea level could be between 0.18 and $0.59 \mathrm{~m}$ higher than present by the end of the 21 st century. In this respect, the $0.2 \mathrm{~m}$ level rise used in the present work, which was derived from the Northern Pacific Ocean General Circulation Model (NPOGCM) A1B scenario (2008) published by JMA, can be seen as conservative. Some authors, such as Vermeer and Rahmstorf (2009), argue that sea level rise could be in the range of 0.81 to $1.90 \mathrm{~m}$ by 2100 , which would mean that the amount of potential damage that typhoons cause to Tokyo bay would be much greater than shown in the present simulation (a perspective shown for example in Hoshino et al. 2012). Thus, although Figure 9 shows that most of the future increase in water levels due to the passage of a typhoon will be due to stronger winds, if higher SLR levels are considered (such as those by Vermeer and Rahmstorf (2009) then this could greatly increase the level of the water during the passage of the typhoon, further increasing the threat they pose to the cities around Tokyo Bay.

It is also worth noting that the strength of the "typhoon bogus" was not increased before it entered the simulation area. In the future, if SSTs increase they will do so throughout the planet, and thus it is likely that a typhoon with the same return period as that of Fitow2007 will be much stronger even before it arrives close to Tokyo Bay (as it would have encountered higher SSL temperatures throughout it life, and not only close to the point where it dissipates after making landfall). Thus, the present simulation in essence is showing the effect of a typhoon with a lower return period (i.e. more frequent) than Fitow2007, which would be arriving close to Tokyo Bay with the same intensity as Fitow2007, but then increasing in strength relative to this historical event. It could thus be said that typhoons in the future will preserve (or even increase) their strength for longer as they approach Tokyo Bay, and this can have severe consequences to the damage these events can cause, requiring coastal defences to be built to a higher level than they are today.

\section{CONCLUSION}

In present study a new simulation methodology to calculate storm surges, based on an accurate simulation of a typhoon's wind, wave and pressure fields, was introduced. The model was verified by comparing it to the storm surge that took place during the passage of typhoon Fitow through Tokyo 
Bay in 2007. Good agreement was obtained between the observed and simulated water levels in the Bay, especially when compared to traditional storm surge simulation models.

In addition, the model was extended to allow for the simulation of future typhoons by taking into account the effects of climate change and sea level rise. For this, typhoon Fitow in 2007 was compared to a similar event arriving in the same computational domain in the year 2100, but taking into account increases in SLR and SST inside this domain. Wind speed due to typhoons is expected to become higher by the year 2100 inside the Tokyo Bay area due to these increases in SST. As a consequence, the wave heights and the storm surges are also expected to become higher, and through the model proposed it was possible to quantitatively compare the wave and storm surge between present day and future events. When sea level rise is taken into account, the surface of the water is likely to be $1.5 \mathrm{~m}$ higher during the passage of a typhoon that arrives to the vicinity of Tokyo Bay with the same strength as Fitow in 2007, compared with the height of the historical event. This will require the strengthening of storm surge defences throughout Tokyo Bay, as they are unlikely to be able to cope with such increased water levels (as outlined also in Hoshino et al. 2012).

An important consequence of this increased in typhoon strength is that the wave heights due wind will increased considerably, and these make up for around $80 \%$ of the increase in water elevation. Also, the significant wave period will become 1 second longer than 2007. If the wave period becomes higher, it is possible that damage to coastal structures due to long period waves will increase, such as the collapse of Seisho Bypass in Kanagawa Pref., Japan by typhoon Fitow in 2007. Thus, a more detailed assessment of the available countermeasures and how they can withstand long wave periods will also be needed in the future.

In present study, only one climate change scenario (A1B) was used to modify the SSTs and sea level rise around Tokyo Bay in the year 2100, but many scenarios that predict future climate change have been proposed by a number of authors. It is possible to also use the current methodology for a variety of other scenarios by taking into account a range of changes to the local weather, sea conditions and temperature, and thus it can prove a good procedure to identify the consequences of changes in typhoon intensity to coastal areas around the world.

\section{ACKNOWLEDGMENTS}

The authors would like to acknowledge the kind financial contribution of the "Disaster Analysis and Proposal for Rehabilitation Process for the Tohoku Earthquake and Tsunami” Institute for Research on Reconstruction from the Great East Japan Earthquake/Composed Crisis Research Institute from Waseda University Research Initiatives.

\section{REFERENCES}

Bureau of Port and Harbor Tokyo Metropolitan Government (win, wave and tide); http://micossa.jwa.or.jp/metro/tokyop/topframe.htm Accessed 11 November 2012.

CISL Research Data Archive (2012); http://rda.ucar.edu/datasets/ds083.2/ Accessed 11 November 2012.

Esteban, M., Webersik, C., Shibayama, T. (2009) "Methodology for the Estimation of the Increase in Time Loss Due to Future Increase in Tropical Cyclone Intensity in Japan", Journal of Climatic Change, Volume 102, Numbers 3-4,pp. 555-578.

Esteban M. and Longarte-Galnares, G. (2010) "Evaluation of the Productivity Decrease Risk due to a Future Increase in Tropical Cyclone Intensity in Japan”, Journal of Risk Analysis, pp. 1789-1802.

Hoshino, S., Esteban., M., Shibayama, T., Mikami, T. and Takabatake, T. (2012) ; Climate Change and Coastal Defences in Tokyo Bay. Proc. of 32nd Int. Conf. on Coastal Engineering (ICCE 2012), Santander, Spain.

JMA (wind): http://www.data.jma.go.jp/obd/stats/etrn/index.php. Accessed 11 November 2012.

Kato, H. (2005): 高潮危険度評価に関する研究, Paper of National Institute for Land and Infrastructure Management in Japanese, No.275, http://www.nilim.go.jp/lab/bcg/siryou/tnn/ tnn0275.htm

Knutson, T., McBride, J., Chan, J., Emanuel, K., Holland, G., Landsea, C., Held, I., Kossin, J., Srivastava, A., \&Sugi, M. (2010). Tropical cyclones and climate change Nature Geoscience, 3 (3), 157-163 DOI: $10.1038 /$ ngeo 779 
Mase H., Katsui S,. Yasuda T,. Tracey H. TomandOgawa K. (2006): Verification of GFS-WRF-SWAN Wave prediction system by three season's comparison, Journal of JSCE, Ser. B3 (Civil Engineering in the Ocean) in Japanese, 22, 109 - 114.

Mase, H,.Muto, R,.Mori, N,. Kim. S,. Yasuda, T (2011): Storm Surge Simulation due to Isewan Typhoon using Detailed Meteorological Re-analysis Data, Journal of Japan Society of Civil Engineers, Ser. B2 (Coastal Engineering), JSCE in Japanese, 67-2, 401 - 405 NOWPHAS (wave and tide): http://www.mlit.go.jp/kowan/nowphas/index_eng.html Accessed 11 November 2012.

Yoshino, J・Murakami, T,. Hayashi, M,. Yasuda, T,. (2005): 沿岸地域における台風災害軽減のた めの台風強度予測手法に関する研究，Journal of Japan Society of Civil Engineers, Ser. B2 (Coastal Engineering), JSCE in Japanese, 57, 1226 - 1230.

Yoshino, J,. Iwamoto, S,. Murakami, T,. Yasuda, T,. (2011): Dynamic Estimation of the Maximum Potential Wind Speed in the Bay of Tokyo Based on the Typhoon Potential VorticityBogussing System, Journal of Japan Society of Civil Engineers, Ser. B2 (Coastal Engineering), Vol. 67-2, pp. $411-415$.

Matsumoto K., Takashi T., and Ooe M. (2000) : Ocean Tide Models Developed by Assimilating TOPEX/ POSEIDON Altimeter Data into Hydrodynamical Model, A Global Model and a Regional Model Around Japan, Journal of Oceanography, Vol.56, pp.567-581.

Mikami, T., Shibayama, T., Esteban, M. and Matsumaru, R., (2012); Field Survey of the 2011 Tohoku Earthquake and Tsunami in Miyagi and Fukushima Prefectures, Coastal Engineering Journal (CEJ), Vol. 54, No. 1.

Mori, N., Takahashi T., Yasuda T., Yanagisawa H. (2011): Survey of 2011 Tohoku earthquake tsunami inundation and run-up, Geophysical Research Letters, Vol. 38, L00G14, 6 pp.

Hoshino S., Esteban M., Mikami T.,Takabatake T., Shibayama T. (2011): Effect of sea level rise and increase in typhoon intensity on coastal structures in Tokyo Bay, Proceedings of 6th International Conference on Coastal Structures, pp. 43-44.

Pielke Jr., R. A. (2007) Future Economic Damage from Tropical Cyclones. Sensitivities to Societal and Climate Changes, Philosophical Transactions of the Royal Society, DOI:10.1098/rsta.2007.2086.Pielke., R. A. and Landsea C. W.(1998); Normalized Hurricane Damages in the United States: 1925-95. Weather and Forecasting, 13, 621-631.

Sasaki J., Ito K., Suzuki T., Utami R., Wiyono A, Oda Y., Takayama Y., Yokata K., Furuta A., Takagi H.(2012): Behaviour of the 2011 Tohoku Earthquake Tsunami and Resultant Damage in Tokyo Bay, Coastal Engineering Journal (CEJ), Vol. 54, No. 1

Shibayama T., Okayasu A. and Toki M. (1990): Storm surge calculation by using 2-level model in Tokyo bay.,Jornal of JSCE, Ser. B3 (Civil Engineering in the Ocean) in Japanese, 6, 77 - 82.

SWAN (Simulating Waves Nearshore): A numerical wave model forobtaining realistic estimates of wave parameters in coastal areas,lakes and estuaries from given wind-, bottom-, and currentconditions (online), Delft University of Technology, http://fluidmechanics.tudelft.nl/swan/default.htm, Reference May. 20. 2012

Takagi H., Kashiwabaya H., and Tomoya S.(2009): Quantitative Evaluation of Vulnerabilities in Coastal Structures due to Climate Change -Case Studies for Breakwaters-, Journal of coastal engineering, JSCEin Japanese, 65-1, 891 - 895

Takagi, H., Kashihara, H., Esteban, M. and Shibayama, T. (2011) ; Assessment of Future Stability of Breakwaters under Climate Change, Coastal Engineering Journal, Vol. 53, No. 1

Vermeer, M. and Rahmstorf, S.(2009); PNAS 2009;106:21527-21532

WRF (Weather Research and Forecasting): A mesoscale numericalweather prediction model (online), NCAR (the National Center for Atmospheric Research), http://wrf-model.org/, Reference May. 20. 2012 